\title{
Social Circumstances of Deviant People, Case Study in Gjakova Region
}

\author{
Bekim Avdiaj \\ PhD Candidate, European University of Tirana, mobile tel. +377 44179369 \\ bekimi4324@hotmail.com \\ $\mathrm{PhD}$ Candidate at European University of Tirana
}

\begin{abstract}
One of the factors influencing groups to hold together as one united 'body' for a social stability, is also the level of appearance of criminality within the region. Alongside evolution of the society, crime has also evolved and refined. Therefore, in the modern world of technology and science, criminality emerges in most diverse and most advanced forms. Based on that, criminality is encountered in every pore of society, irrespective of development, tradition, culture and nationality, and that from the local level, regional, state and all the way to international dimensions. This is furthermore sustained particularly by social evolutions experienced by the countries in transition, which were subject of a 'reformation' in all social spheres thus without sparing the human values. These trends of global development have, through some deviant cases, resulted with situations where all the existing social norms are being relinquished. Regardless of where you may happen to be, whatever newspaper you read, whatever news edition you watch on TV, one cannot but note that various criminal offences are being discussed or reported about, starting from the most common ones all the way to the terrorist acts. Based on the number and type of criminality, and based on the number of deviant persons, from 1999 onwards Gjakova region results with entirely new 'behaviour' in this direction. Therefore, current studying and analysing of social circumstances related deviant persons of this region consists of an immense and specific importance. Social circumstances and other factors of such persons shall be reflected through this study and that from the analysis generated from 95 of them which, in relation to the number of criminal offences reported with the law enforcement authorities from 2001 until 2012, appears to be $0.41 \%$. The sample included convicted deviant persons coming from the population of Gjakova region.
\end{abstract}

Keywords: social, criminality, social development and Gjakova region

\section{Introduction}

The present-day social development trend has increased the complication and complexity in the society. Moreover, various criminal activities and occurrences turn up to be even more complex, in particular when they represent a 'cut' between the past, present and the future. Based on the literature on criminology, there was a long-time-persisting opinion that only unstable social strata and individuals belonging to a rather poor economic situation dealt with criminality. This theory is nevertheless dismissed given that individuals from higher social strata and of good economic situation have been lately involved in criminality. Therefore, 'modern' criminality knows no boundaries in sex, age or in economic situations or social strata. These have oftentimes generated social conflicts of scales even dangerous to life and property in global level.

Human-being way of life and thinking is formed and stabilized under the influence of social and economic conditions of a certain period of time (Krasniqi, 1990:297). By way of change of economic and social conditions, especially with the most recent technological developments in all spheres of social life, it is by all means imposed a change in the way of living, in the positive sphere as well as in the negative one and this is an unceasing process. 'Modern' societies in the contemporary world confront with ever increasing criminal activities. Some of such criminal activities dwell on use of violence all the way to the most severe aggressiveness. Gjakova society suffered exactly these activities after the war of 1999. Based on the above it results that an individual's personality, besides behaving within the frame of ordinariness, can also often exhibit negative behaviour, i. e. to deviate. 
Many a studies have been hitherto conducted in relation to goading of individuals on such behaviour, violating norms and laws of the concerned society, where according to sociological explanation such deviances are learnt during the course of life in society. Nowadays it is not the human being living in caves and kindling fire by way of 'friction', but it is the human being living in one-hundred-storey skyscrapers, the human being flying spaceships in conquering the universe or piloting submarines in exploring the sea and ocean life. Thus, "while the cultural environment we are born and grow up in influences our behaviour, it may seem that we are with no individuality or free will" (Giddens, 2004: 94).

Therefore, this beginning of the century has started with an even bigger increase of perils to human life. We now have not only the natural risk but also the risk from the very developments of the society. Today, "development, modernization, the increasing quality of life culture, are faced with some eminent natural and social liabilities, which have engaged to a full meditation the society, politics, the state and everything" (Tushi, 2006: 379).

Dealing with criminality was a subject of many a authors and researchers since the early times, labouring to understand such actions. The very infringement of life and material goods has led to such dealings purposing to avoid such risks. These forms and reactions have been made based on the circumstance of the time and depending on the social developments, which every once in a while suffered radical change.

Criminality, as an occurrence dangerous and harmful to the society, has been at the epicentre of many a philosophers and scientists since primeval times. Thus, opinions in relation to this occurrence and causes of its presence begin from the primordial points of views of ancient Greek philosophers (Halili, 2002: 69), although there were even earlier opinions continuing to the present days.

Various and numerous opinions have been provided in relation to criminality since ancient times and they continue to the present days and such are opinion from renowned researchers in this field. Various researchers have also provided from most diversified definitions to the most alike ones. Such a statement is also asserted by prof. I. Salihu, according to whom: "though they agree on the general definition of phenomenology, some differences exist amongst them" (Salihu, 1985: 125).

With regard to criminality, ideas and opinions have been provided since ancient times. Plato assesses that the impact of ill instinct and soul bring strong emotions and lusts with certain individuals who commit crimes. Based on this, he goes as far as a prevention of criminal occurrences may be achieved only if it is permeated through the inner psychological side, and in addition, he assesses also some of the external factors.

The issue of criminality was dealt even by Aristotle, who assessed that the way of organizing a society plays a role in this matter. Amongst the scholars who elaborated on this occurrence was also J. Jacque Rousseau who claimed that the causes of criminality and ways of preventing criminality lay within the social conditions and circumstances of the perpetrators of criminal offences. According to him, a human being is not born as a criminal but rather the society and societal environment as well as socio-political conditions and circumstances drive him in conducting criminal behaviour and committing criminal acts (Halili, 2002:74). This view parallels also with the current reality in Gjakova region. Based on this reality currently we currently have concrete criminal behaviour and activities which are a result of the of the social environment, social and political circumstances and conditions.

In addition, viewpoints which, from their appearance to the present day, represent and provoke debates and critical discussions are the viewpoints of sociologist $\mathrm{E}$. Durkheim. According to him, the causes and roots of crime are in the very nature of human society, in the social surroundings and in the want of social control. Criminality is characteristic to every society and it is a loyal companion of all human societies. He goes as far as underlining that: the society in which criminality has decreased is in an unhealthy and not normal social situation. Such society lacks processes and manifestations that drive forward the development of the society (Vold, Bernard, Snippes, 1998: 124-126).

Gabriel Tad provides his viewpoint on criminality advising that the main cause of its appearance are "social circumstances and problems in adapting to the existing life conditions", where he emphasizes "the process of imitating and learning criminal behaviour" (Halili, 2008: 95). That criminality emerges from the society itself, is also asserted by the philosopher Emil Dyrkheim, according to whom: "cause of criminality and its roots are in the very nature of human society, in the social environment and in lack of social control" (Halili, 2008: 96). 
One of the key measures in combating criminal occurrences is the identification of factors that abet individuals in criminality. An assessment on criminality is also provided by Giddens expressing, amongst the rest, that: "In the recent years there have been attempts to use an interpretation with rational choices in analysing of criminal offences. This implies that people are not goaded in criminal activities, but in an active manner they chose to engage in them. They believe it is worth of taking a risk. Persons having "criminal mentality" are those who envisage profit from situations when they break the law, or while being conscientious of the risk they may be apprehended" (Giddens, 2004: 136).

\section{Social Circumstances Change and Impact}

Since its very rise, human society has been confronted with and continues to be challenged by change, many times also facing with breaches of rules, norms and existing laws. Therefore, incidents started occurring as of the age of the first human society, infringing thus the rules of social life based on the customary law. In order to safeguard of these activities it was necessary to react towards the persons committing such activities. For this reason, the criminality phenomenon is an issue that provoked many a researcher to deal with it, "it is a constant negative occurrence which has accompanied human society from the first primitive community to the present day (Hajdari, 2004: 189).

Referring to the most recent studies in the aspect of criminology, criminogenic factors of appearance of antisocial and criminal occurrences in a society are the factors that affect significantly the occurrence of criminal behaviour, and they are: the economic-social group of factors, ideo-political factors, micro-group factors, socio-pathological factors and others (Millutiniviq, 1985: 375-376).

Many a researches have been conducted to the present with regard to instigation of individuals in such behaviour, breaching norms and laws of a certain society, where according to the sociological explanation these deviances are learnt while living in the society. With regard to social change, it results that there are three main segments that cause social change: physical environment, political organizing and cultural factors. Moreover, many observers have suggested that what is taking place nowadays is transferring to a new society which no longer bases itself on industrialism. They claim that we are entering a development stage that is beyond the industrial one (Giddens, 2004: 619).

\section{The Overview of Social Circumstances of Deviant Persons in Gjakova Region}

Age: Referring to the data released by research, it results that we have to do with the involvement of all ages that have been the subject of legal violations and that in satisfactory percentage of all categories. This shows that deviate behavior knows no age.

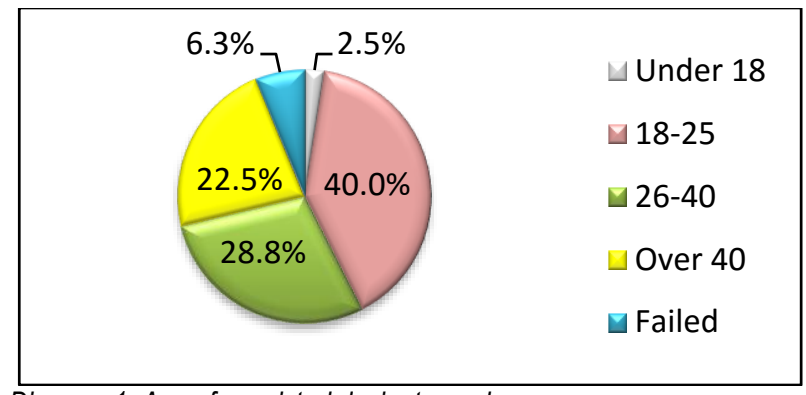

Diagram 1. Age of convicted deviant people

Gender: Many texts in criminology still include almost nothing for women, except for rape and prostitution parts and most of the theories of avoiding are leaving women almost aside. Although women are less likely to participate in avoiding activities than men, it cannot be the reason to leave out of consideration (Giddens, 2004: 145). However, the recent social developments in the field of crime have involved the deviants regardless of gender, resulting that the subject of legal violations were both sexes. 


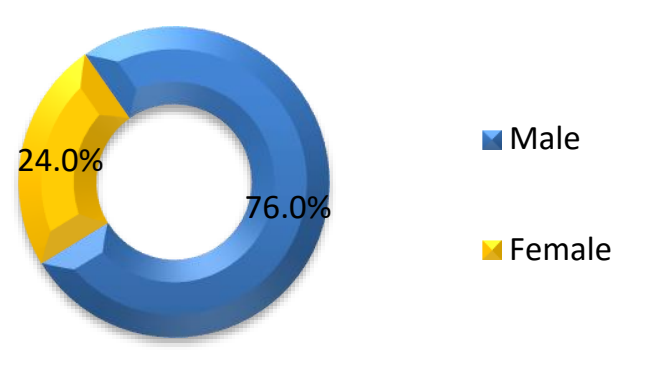

Diagram 2. Gender of convicted deviant people

Education level: During the field research it appears that in criminality have been included all levels of education. This proves that in the 'modern' world, from deviant behavior to the crime are involved not only citizens with a low level of education, but also them with a higher level. This comes as a result of developments in technology and the most diverse businesses. So it turns out that crime has raised the intellectual level and that today not only those who do not have education are committed to crime.

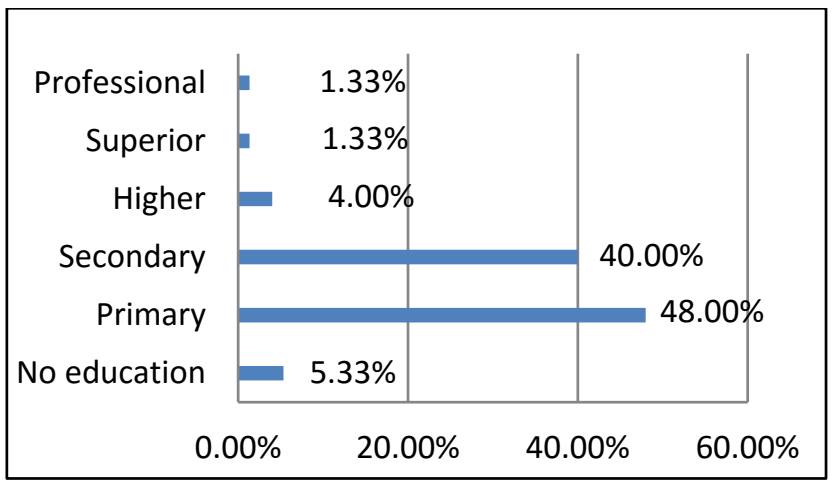

\section{Diagram 3. Education Level}

Marital status and family: It seems that we are dealing with the champion that is part of a broader community and less belongs to individuality. We are dealing with people who are basically part of the family. Considered in social terms, this is the category that has no obligations to many others, but it is precisely this category that deals more with society.

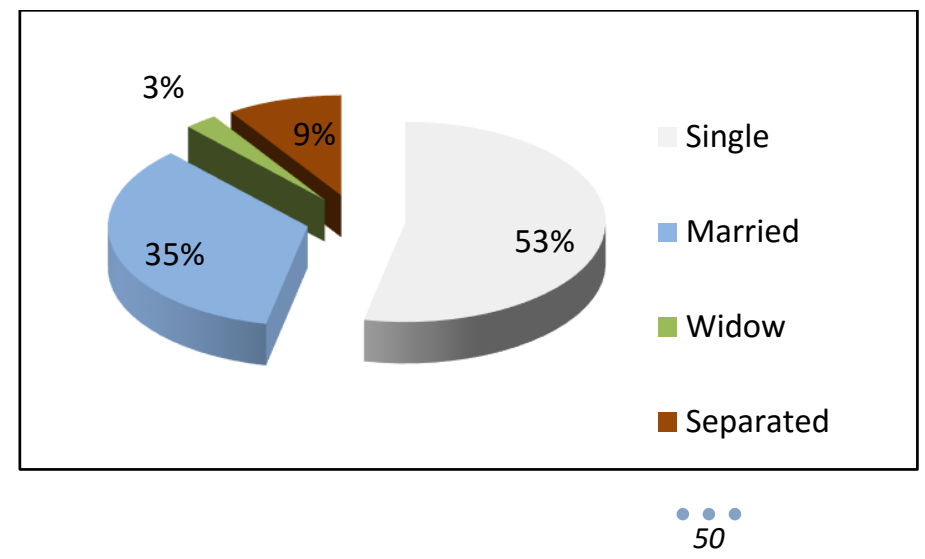


Diagram 4. Martial status

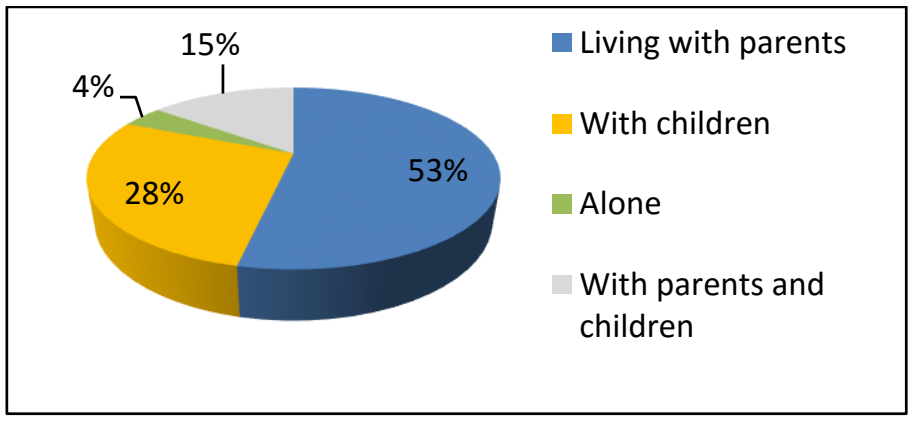

Diagram 5. Family status

Residence: Considering that the evolution of social and criminal acts have involved roughly the same as the urban area, as well as the rural areas, we have inclusion sample from both areas. It dominates the urban areas because of greater population, where population is concentrated after 1999, given that during these years there have been numerous internal migrations, where the city is populated by the population of rural areas.

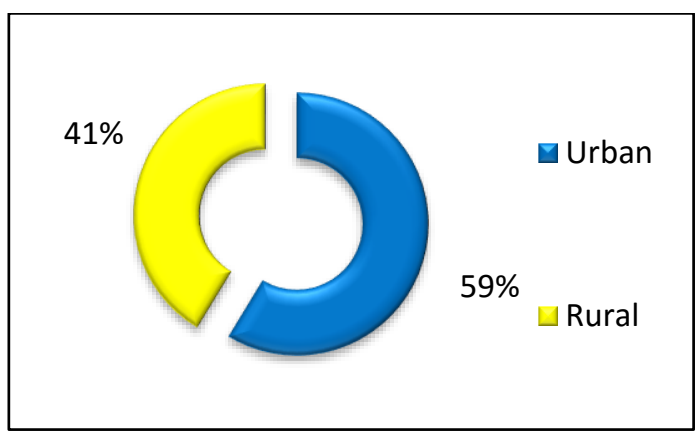

\section{Diagram 6. Residence}

Employment status and economic situation: Based on these, we see the prisoners come not only from the poor economic situation, but also from the medium and good levels. This presents an interesting feature on encouraging various individuals and groups in order to insert the path of crime, where it appears that not only persons whose survival security was imposed through criminal activities, but in crime, much more, are being encouraged people dealing with such activities only for faster enrichment, and there are those who do the dirty work just because of passion. 


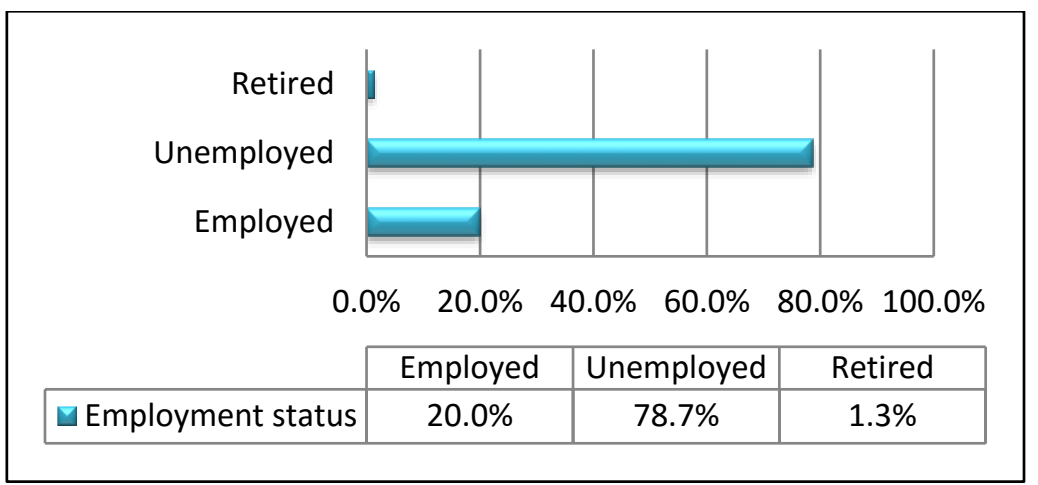

Diagram 7. Employment status

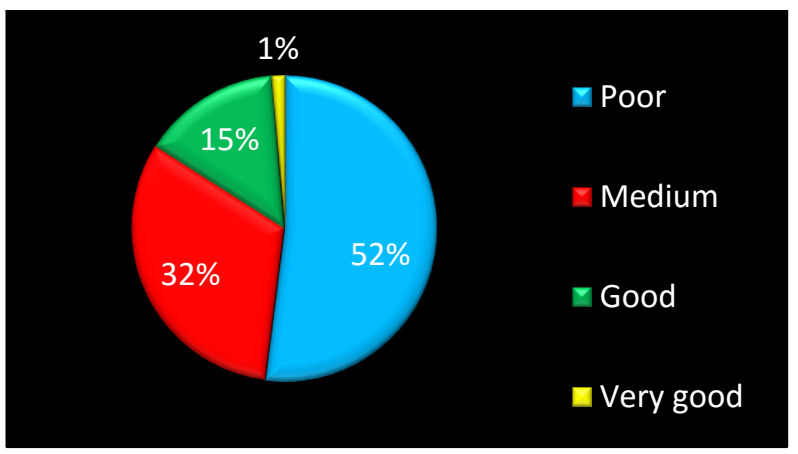

Diagram 8. Economic situation

Other residence and legal violations: Considering that soon after the intervention of the international community in Kosovo and governance during the transition period of this society, even after the declaration of the state of Kosovo, many people from different countries of Europe, and other countries, have returned voluntarily or with eviction in their place, among which in Gjakova, many people have been convicted abroad and other habitats.

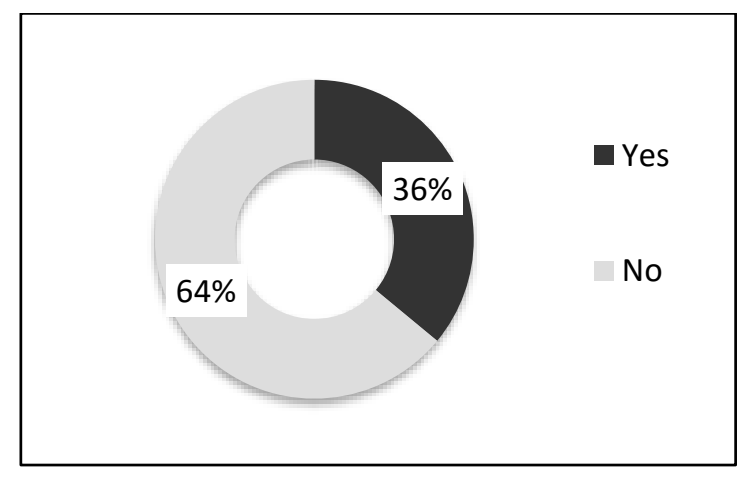

Diagram 9. Abroad residence

From this sample, it appears that there is a large number who have lived in different countries of the world and have knowledge on developed and open societies and they had to do with violations in these countries. 
Legal violations: People convicted into the sample of dealing with violations, which itself are proved by the data questionnaire.

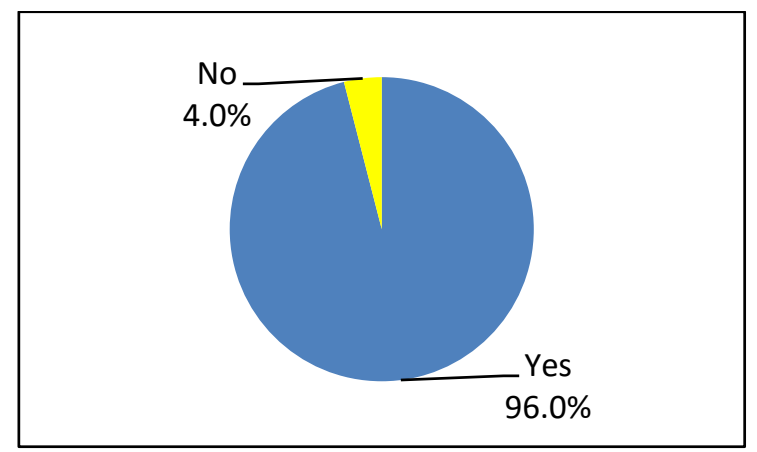

Diagram 10. Legal violations

In the second half is treated the decline against the law, arrests and punishments, where we have: $96.0 \%$ of them admit that they have violated the law.

Arrested: By these people a large percentage of them have been arrested, which arrests were attributable to periods of pre-war, post-war and from both periods, but the one which dominates is the time after 1999.

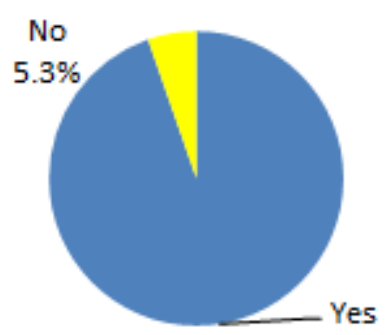

$94.7 \%$

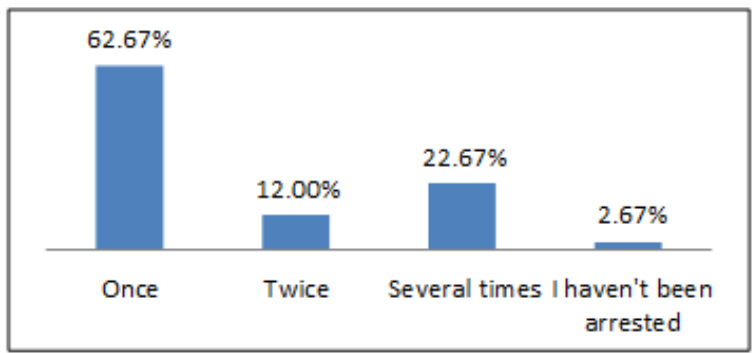

Diagram 11. Arrested Diagram 12. Times - arrested 


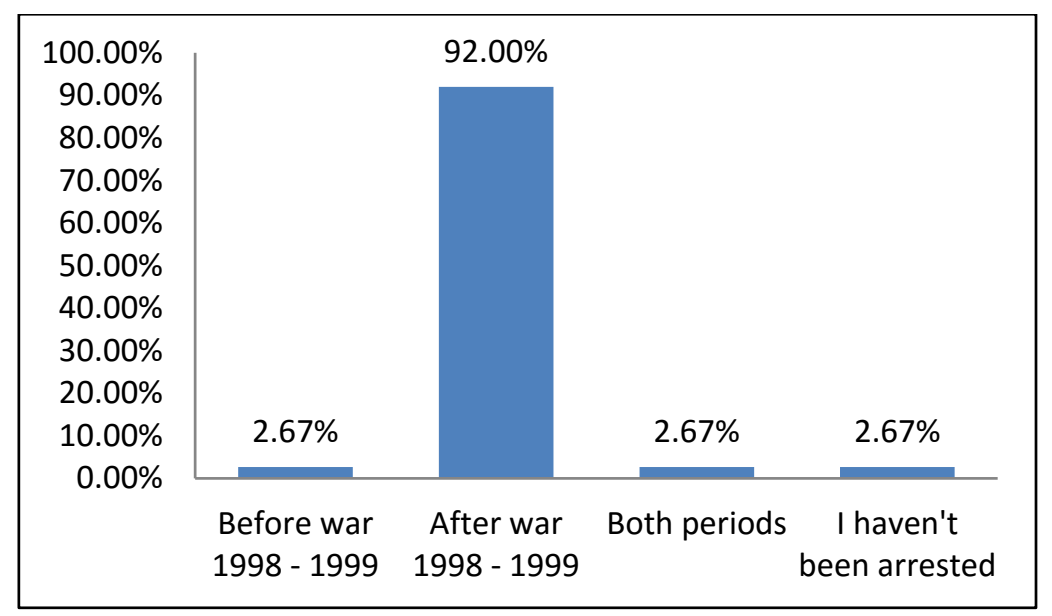

Diagram 13. Arresting period

Here can be seen that most delinquent are teenagers and that a number has been arrested several times.

Convicted: From this sample it appears that almost all were also convicted, and not just once. Also periods in which they have been convicted range from once to several times
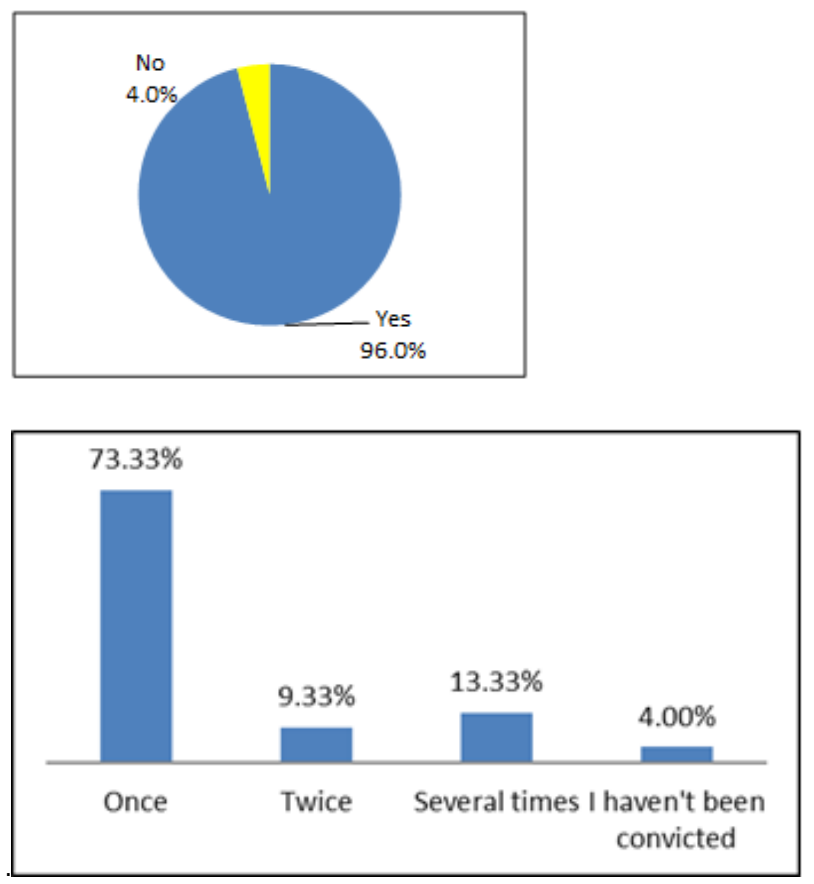

Diagram 14. Convicted Diagrami 15. Times - convicted 


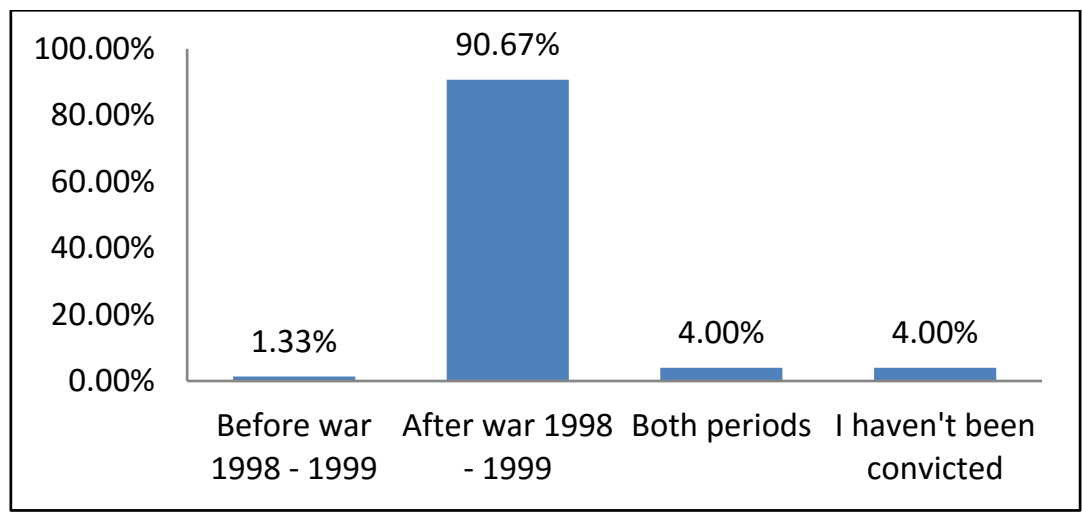

\section{Diagram 16. Convicting period}

This shows that the concerned people have criminal records, in which dominates the only once punishment, but there is also present and worrying fact when there are convicted people two, three or more times. This proves for repeat offenders who are not reaching the proper socialization. Then, there dominates the 1998-1999 period of post-war punishments, but there are those who have been convicted even before that period and also in both periods. What is striking is that some have written that have not been arrested. This is reportedly due to two reasons: first some thought to evade reality and secondly, there are times when after the offense they have not been arrested, but they were presented themself in the justice institutions and from there they took measure of punishment.

\section{Arrested and convicted familiars:}

Based in criminological literature it is stated that a major role in the appearance of crime and criminality also plays the social environment. According to professor of forensic Alexander Lakasanji, social environment breeds crime and criminal culture is the environment microbe. Here is emphasized more the role of social factors in comparison to the economic and underestimates individual aspects of crime, especially the personality of the perpetrator. Therefore it is obvious that they have an accompanying heritage from their family members in violation of social norms.

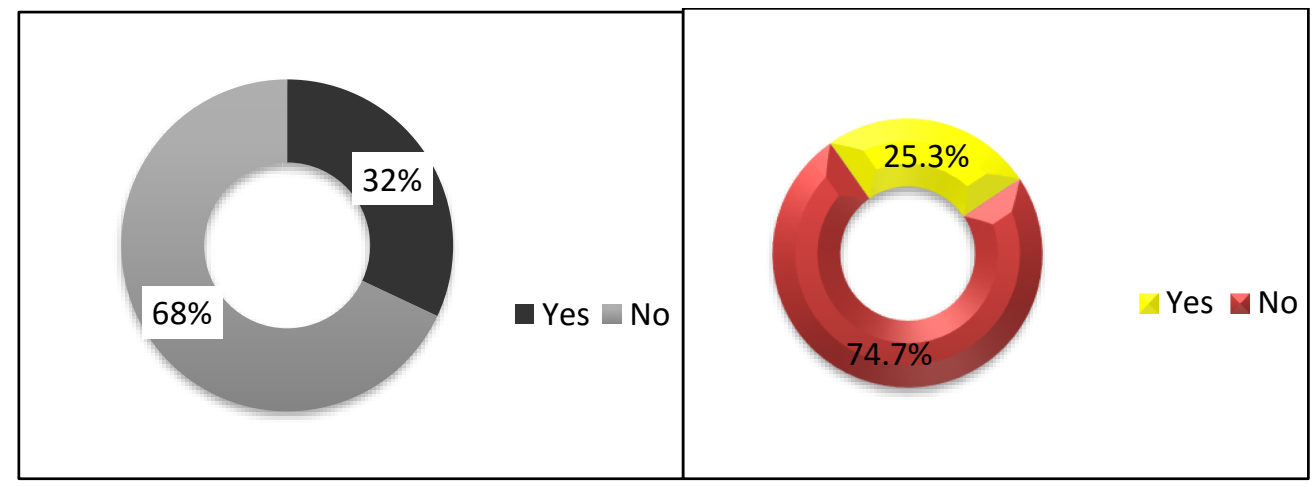

Diagram 17. Familiars arrested Diagram 18. Familiars convicted

Arrested or convicted by society: It seems that convicted people have had arrested and convicted people as their friends. This could indicate that they have a good cooperation between themselves and also the time they spend together. In fact, they make you realize that they might be a model of each other, encouraged in criminal activities. It is understood that the influence of society and the environment has an important role, especially among the youth. 


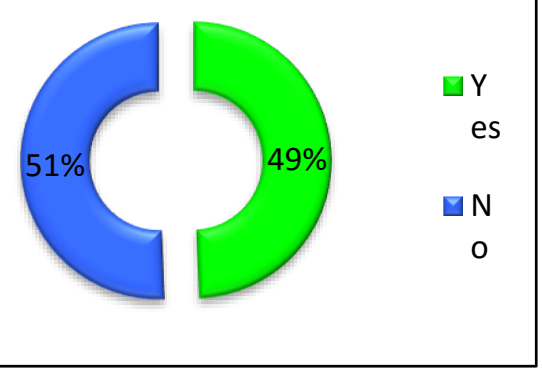

Diagram 19. Arrested and convicted by society

\section{Conclusion}

The trends of criminality are increasing in almost all societies of the world. Despite numerous attempts carried out by subject-matter experts and various sciences of this field with regard to identification of causes and required measures to at least alleviate it a trifle, it has remained only an attempt though hoping to be accomplished. In the recent times at the beginning of this century, crime inclination has brought many new forms that are dangerous to the humanity. These forms appear to be dangerous and lethal, because the very technology used by crime perpetrators is very sophisticated and involves devastating dimensions, both against property and against the life of persons, causing innumerable victims. This does not exclude the level of crime in a barbarous manner that existed since antiquity; however, the magnitude of victims in modern times is overwhelming.

Based on the statistics and the data of this study, it results that the number of persons that venture in deviant behaviour and criminality is increasing. It appears that an important factor is age and sex, where it is obvious that there is significant percentage of all the ages, but young ages are the leading ones; on the other hand, there is also a considerable percentage of female sex as well. This proves that criminality turns out to be tempting, which inexorably represents perils and creates instability in the society of this region.

Referring to theories that usually in criminality are involved persons lacking education, persons with no family supervision and of poor economic situation, it results here that social change in this region have brought novelties in this region. Currently, criminality embroils also persons of even highest intellectual degrees who live in family unions and who have a rather good economic situation.

There are persons who have also lived abroad, outside Kosovo, for a extended period of time and who have been engaged in criminal occurrences, who have not returned and continued to be engaged in their 'trade'. They have adapted very quickly and have created friendships with others by becoming successful co-operators.

Concerning is the fact that the vast majority of convicted persons are recidivists, who have been arrested and sentenced more than twice. This indicates that we have to deal with 'professionalism' and that re-socialising institutions are not at all efficient.

Continuation of family tradition in the field of criminality is also not wanting; nevertheless, there are also a great number of them coming from well-boding families. It appears here that their company has an influence, as it results that many of them socialise with persons having criminal background.

\section{LITERATURE}

\section{Primary Literature:}

George B. Vold, Tomas J. Bernard, Jeffrey B. Snippes, (1998). Teoritical criminology. New York: Oxford. 
Giddens, Anthony (2004). Sociology. Tirana: Çabej.

Hajdari, Azem (2004). Kriminaliteti i të miturve në Kosovë gjatë periudhës 2001-2003. [Criminality of Juveniles in Kosovo During the Period of 2001-2003]. Prishtina: University of Prishtina.

Halili, Ragip (2002). Kriminologjia [Criminology]. Prishtina: University of Prishtina/ Law Faculty.

Halili, Ragip (2008). Kriminologjia. [Criminology] Prishtina: University "Fama”.

Krasniqi, Mark (1990). Disa ndryshime bashkëkohore në traditën fshatare në Kosovë nën ndikimin e faktorëve ekonomikë. [Some Contemporary Changes in the Rural Tradition in Kosovo under the Influence of Economic Factors]. At: Ethnographic Study of Contemporary Changes in the Albanian National Culture. Prishtina: Institute of Albanology - Prishtina.

Milutinovic, Milan (1982). Kriminologjia. [Criminology]. Prishtina: ETMMK.

Salihu Ismet (1985). Vrasjet në KSAK. [Murders in SAPK]. Prishtina.

Tushi, Gëzim (2006). Probleme dhe dilema sociale. [Social Problems and Dilemas]. Tirana: Dudaj.

Additional Resources:

Yearly Reports of Gjakova Police from 2002-2012 